\title{
Managing School Based Studies in Namibia's Zambezi Region: Navigating Challenges in the Practicum Triad
}

\author{
Africa Zulu \\ Department of Education in Languages, Humanities and Commerce, \\ Faculty of Education, University of Namibia \\ zuluafric@gmail.com, azulu@unam.na \\ Mutendwahothe Walter Lumadi \\ Department of Curriculum and Instruction, College of Education, University of South Africa \\ lumadmw@unisa.ac.za
}

\section{Doi:10.5901/mjss.2014.v5n20p2841}

\section{Abstract}

This study examined the challenges besetting the teaching practicum and the varying roles of individual members of the practicum triad comprising the university, the student teacher and the support school during the practicum component of primary teacher education at the University of Namibia's Katima Mulilo Campus, Zambezi Region. It sought to establish the perceptions of university lecturers and support teachers about the effectiveness of the pre-deployment preparedness of student teachers before their attachment to practicum schools and to as well establish the facets of the school participation within the triad which are most effective in supporting student teachers throughout their school based practicum. Suggestions from support teachers, student teachers and the University of Namibia's Faculty of Education were collated in efforts to foster an effective practicum partnership. This study thus posits a view that school-based teaching practica should provide the preservice student teachers with opportunities to be exposed to the contextual realities of teaching and other related professional activities through the development of sustainable norms and a continuum of realistic practicum partnerships which should take on board all stakeholders.

Keywords: Practicum, triad, parameter, support teacher, student teacher.

\section{Introduction}

This study was undertaken at a time when the University of Namibia had just merged with former Colleges of Education, ostensibly as a strategy to improve the quality of primary teacher education in Namibia. This was a result of a cabinet resolution aimed at phasing out the Basic Education Teachers' Diploma in favour of a Bachelor of Education (Honours) degree as the basic qualification for all practising teachers in Namibia. To achieve this, the University of Namibia was mandated to take charge of the training of all school teachers in Namibia. Previously, the university was only responsible for training secondary school teachers while colleges, under the auspices of The Ministry of Education, were responsible for training all primary school teachers. However, the merger came along with a host of challenges which included the reestablishment and re-definition of partnership roles for relevant stakeholders, the selection, placement and assessment of student teachers during the teaching practicum (Masule, 2011). Cohen, Manion, Morison \& Wise (2010) argue that effective pre-service teacher training occurs when there is in place a functional collaboration between training institutions and schools. Members of such collaboration should work out a model that sets out each member's roles.

In conducting this research, the researchers took into consideration the various learning theories, including those that emphasize the role of environmental influences on learning. Within this framework, the student learns through a variety of ways and in a wide range of environmental settings. Through this theoretical concept, the student's learning is shaped by the influences of, among others, support teachers, university lecturers, peers and community leaders each of whom will socialize him/her appropriately.

Theories that deal with environmental influences on learning are quite ideal and helpful in the research of teaching practicum due to the fact that teaching practicum takes place in particular environmental settings. Specifically, it takes place at authentic workplaces- the school. At real workplaces, the expert (principal, support teacher, etc.) is the person best positioned to share occupational experiences with trainees and novices. In such a setting, teaching practicum can be 
structured to effectively facilitate the transfer of skills, knowledge and attitudes.

\section{Literature Review}

The term practicum is used by many institutions to refer to a requirement where students are exposed to a teaching experience in a school or learning institution where they get an opportunity to interact with real learners. The teaching practicum has traditionally been viewed as central to the development of student teachers' pedagogical skills, initiation into the teaching profession, and as the most effective component of professional preparation for the role of a teacher (Cruickshank \& Aramalin, 1986, Tannehill \& Zakrajsek, 1988). Many teacher educators believe that it is during this experience that student teachers begin to develop their teaching skills, beliefs and values (Darden, Darden, Scott \& Westfall (2001).

The student practicum is critical in teacher education due to the many reasons and functions it performs. For example, it is a vital tool for providing a practical exposure to the reality of the world of work. Student teachers can rehearse what they will be doing in the real context of a mainstream institution like a school or college when they eventually take up their teaching assignments. Purdy and Gibson (2008) equate teaching practicum in education to field attachment or internship in medical, legal or engineering professions. The terms "induction" or internship are also applied to describe the practicum experience given to student teachers. Therefore, the terms practicum, teaching practice (TP) or internship essentially mean the same basic idea of deploying the student teachers to natural work stations where they will acquire practical experience. There is a general consensus amongst teacher education scholars that the practicum is a core component of teacher programmes, irrespective of by what nomenclature it is referred by (Mclntyre, Byrd, \& Foxx, 1996; Russell, 2005).

Teaching practicum enables student teachers to develop innovative and reflective thinking and equips them with a repertoire of teaching methodologies and strategies. It also strengthens student teachers' application of behavioural objectives and trains them in using various teaching aids, choosing and organizing learning activities, and applying remedial interventions to given exit learning outcomes (Murtaza, 2011).

A very important dimension of the practicum is that it encourages interaction between the student teachers and the experienced teachers. This interaction enables the student teachers to develop teaching process insights by observing and sharing ideas with the seasoned experts. The practicum presents the student teachers with an opportunity to have model in front of them to follow where they get exposure to professional practices of experts (Zeichner, 2006).

The teaching practicum has traditionally been regarded as pivotal to the development of student teachers' pedagogical skills and to the students' initiation into the teaching profession. According to Taggart \& Wilkinson (1985), student teachers and practicing teachers view their practicum experience as the most vital component of their training. Over a couple of years, it has been argued that the practicum should be based on collaboration, student teachers' empowerment, and reflection in order for the student teachers to realize their potential. This position has witnessed a gradual shift from what Rodgers and Keil (2007) call the traditional student supervision triad, where the teacher educators were the sole goal setters, problem solvers, and decision makers, to a more student teacher dominated approach of enquiry and investigation (Dobbins, 1996). The teaching practicum should also promote collaboration, coordination and cohesiveness among student teachers, university supervisor, and school managers. A very important principle of the practicum is the shared commitment to teacher education between the university and schools.

Villiers \& Mackisack (2011) propose that highly skilled personnel from both the university and school can be identified to spearhead the practicum in a professional and manageable way. If this responsibility is shared, meaningful partnerships to promote informed and effective positioning of the practicum in teacher education programmes will be developed. They argue that "there is no alternative to genuinely and tangibly sustaining partnered, educative mentoring with a professional learning community in order to ensure that student teachers have optimum opportunity to hit the ground running as beginning teachers" (p.193). Tuli \& File (2009) observe that incorporating a practicum component in the teacher education programme enables student teachers to understand the socio-cultural, economic and political factors which underpin education. The practicum should therefore be considered as the core component of teacher training that aims at preparing effective teachers.

Teaching competence will forever be rooted in experience and learning to teach demands that one travels deep into the recesses of one's self-awareness. This demand indicates that the practicum is a vital component of teacher education and is a vehicle for providing such invaluable experience to the student teachers. An effective practicum ought to be allotted an identifiable part of a teacher education programme where teacher education institutions take the leading role in the concept development of an effective practicum model. The partnership model should take on board all relevant professional stakeholders and consists of closely integrated university and school components which lead students to 
develop and demonstrate knowledge-based skills and attitudes which are pivotal to their professional career development.

\section{Method}

This study adopted an ethnographic approach, which is the qualitative study of individuals and groups who represent a particular culture, Springer, (2010). The study took place in the natural settings and information was gathered through a range of instruments such as observations, in-depth interviews and document analysis.

The researchers investigated the university-school-student triad experiences and realities through sustained contact with the triad members; student teachers, support teachers and university lecturers in their natural environment in order to produce rich, descriptive data that helped him to understand those experiences. The study sought to understand this triad by gaining a native perspective from the inside looking around, rather from outside looking inward. This was done by entering the participants' environment, the schools, to observe events, artefacts, and symbols that defined the triad's culture and gave it meaning. This involved a sustained engagement with the research participants to the point of data saturation, while all the time using the grounded-theory approach of recursive data examination while documenting observations in field notes in order to ensure credibility of the findings and address distortions, Lincoln and Guba (1985).

This research employed non-probability sampling which involved the researchers selecting individuals with knowledge of the phenomena under study and cases which they deemed to be information rich. These were made of:

* Eight [8] principals and eight [8] support teachers of eight [8] primary schools around Katima Mulilo,

* Fifty [50] Bachelor of Education students in their second and third year, and

* Ten [10] lecturers from the Faculty of Education. The research sites were the University of Namibia, Katima Mulilo Campus and the eight primary schools.

The primary data collection methods in this study were semi-structured in-depth interviews, observations and document analysis such as the policy statements, prospectuses and handbooks.

Data collected was analysed by organising, accounting for, and noting patterns and consistencies, at the same time observing similarities or differences between individual narratives.

Each of the transcribed interviews was analysed and was followed by the processes of data reduction, data display and then by the drawing and verification of conclusions, (Miles and Huberman, 1994).

The interview data reduction phase attempted to organise and simplify the data into manageable parts. This involved employing first-level and second-level coding techniques (Punch 1998). Kerlinger (1970) as quoted in Cohen, et al $(2011 ; 559)$ define coding as "the translation of question responses and respondent information to specific categories from the purpose of analysis.

The first-level coding examined small and discreet parts of the interview and identified the concepts that were mentioned therein. Interview transcripts were broken down into sentences or groups of sentences which were examined and assigned descriptive labels. Further simplification of data followed in the second-level coding by examining the first level codes and placing similarly coded units into categories which were assigned a conceptual label for the second-level (Strauss and Corbin, 1998). Further simplification was done at the third-level coding where similar conceptual categories were clustered and assigned a third -level conceptual label.

The data display phase was employed to map second- level and third-level categories on a chart in a simplified format to provide a visual representation of the relationships among the categories and to enable identification of emergent key themes from each interview. A further chart was drawn to map key themes which emerged from each interview transcript analysis to enable the researchers to make comparisons across cases.

Emerging themes were drawn and verified from the analysed interview transcripts and similarities and differences which emerged from the comparisons across cases were also drawn. At the end of the data collection and analysis processes, feedback from participants was solicited as regarded the emerging themes. A comparative technique to the phases of data reduction, data display and conclusion drawing and verification was used so as to reinforce the findings of the research (Miles and Huberman, 1994).

\section{Findings and Discussion}

This study established a number of themes pertaining to individual members' understanding of their particular roles within the practicum triad, supervisory challenges which they faced and the effectiveness of student teachers' pre-deployment preparedness for the practicum component of primary teacher education at the University of Namibia. Some themes also emerged about the facets of the practicum which were viewed as most effective in supporting student teachers 
throughout their training.

\subsection{Theme 1: Role parameters}

While the majority of support teachers and university lecturers were quite clear and convincing about their own roles in the practicum partnership, they unwittingly traded accusations that the other party was not doing enough. Lecturers from the university were accused in this study of being disrespectful, pompous and condescending towards their counterparts in the schools. Lecturers would visit their students in schools to supervise or assess students and then leave the school premises without saying a word to the support teachers. According to some of the teachers, this was tantamount to open insult. On the other hand, the university lecturers claimed that the school teachers felt 'inadequate' and had an unnecessary inferiority complex. University policy on assessment of students did not help matters either.

To compound matters, student teachers laid blame on both the university and the support schools. Students are guided by practicum policy documents which they religiously adhere to. However, some students alleged that a few support teachers and lecturers wantonly flout policy and not much is done at a higher level to deter this. The students claimed that some of the support teachers are completely ignorant of the contents of SBS manual and sometimes unofficially delegate students to take on the responsibilities of a fully-fledged teacher.

\subsection{Theme 2: Student supervision and assessment}

Most support teachers felt that the university was not providing adequate pre-deployment preparation to their students. This resulted in the support teachers bearing the arduous task of taking the student teachers through some of the most basic paces of teaching. Support teachers lamented over the amount of student supervision which they are expected to do on behalf of the university which, unfortunately, barely recognises that role. Compounded to this was the lack of adequate supervision from the university during this period. In addition, the university did not contribute to the provision of basic teaching resources such as writing material and other teaching materials. Schools bore the entire burden.

In spite of all their effort, support teachers were not considered 'competent enough' to contribute to the final assessment of the students under their tutelage. The university's School Based Studies policy did not give room for school teachers to give practicum students final assessment grades. Assessment was the sole preserve of visiting university lecturers.

Most lecturers bemoaned the inadequate practicum time at their disposal to offer any meaningful guidance and supervision to their students. They indicated that room and resources were only enough for them to visit their students for assessments; the SBS policy had no provision for them to periodically visit them for guidance. Most disturbing was the claim that lecturers were expected to assess students in subjects in which they themselves were not experts. There were mixed feelings concerning this and other challenges as shown by the responses from lecturers.

Some excerpts from lecturers:

Lecturer $A^{*}$,

"If we are inclusive teacher-educators, we should be able to handle all subjects, especially given that teachers are available at the school and we can call on their assistance. That way, we can also demonstrate that we value our teachers. This issue was discussed several times at Student-Lecturer Fora and TP meetings and every time, the agreement was that we should do all we can to evaluate all our students in all subjects and specializations".

Lecturer $\mathrm{B}^{*}$,

"While in the Y Regions", I have been observing Maths, Biology and Geography among others, none of which are my main subjects; and I had no problems with that. Colleagues, with good will and commitment to our students, we can manage the impossible. All that is required is change of attitude and creativity".

Lecturer $C^{*}$,

"There are great concerns from students who have not been assessed yet in various regions, but especially $X$ Region*. Can the assessors please see to it that all students are evaluated?"

Lecturer $D^{*}$,

"I was one of the members of staff who were assigned to some Region $T^{*}$ schools. At School $A^{*}$, I assessed lessons in 
English, History and Geography. At School B*, I assessed lessons in Biology. At School $C^{*}$, I assessed lessons in Geography, English and Biology. I could not observe lessons in Physical Education at School $C^{*}$ because the subject was not offered at the school- that was what I was told. This was my experience".

\subsection{Theme 4: Lack of Consultations}

Most of the triad members conceded that they rarely conducted formal consultative conferences, besides the casual discussions, which were far and wide apart. Support school authorities waited upon the university authorities to take the lead and initiate meetings. The university lecturers indicated that school teachers exhibited a nonchalant presence in the whole process and that their interest was lacklustre, at best. On the other hand, support teachers claimed that most university lecturers exuded an air of self-importance which made them appear irreproachable.

\section{Recommendations}

In the absence of a 'critical mass' of previous studies in the literature, the current study, therefore, has the potential to make vital contributions to define and expand existing knowledge on triad partnerships in teacher education in Namibia. It is envisaged that this study will contribute significantly to the body of knowledge related to partnerships between teacher training institutions and support or practicum schools, with particular emphasis on professionally coordinated school based studies with the view of developing better understanding and more effective ways of administering teaching practica. Hopefully, the study will enable institutional policy makers to re-define, in broader and clearer terms, role parameters among the practicum triad members.

Owing to the foregoing observations, this study therefore makes the following recommendations:

\subsection{Role parameters}

- As a way of defining lecturers' and support teachers' individual and overlapping roles and responsibilities, regular dialogue between the university and support schools needs to be intensified. This could be in the form of an information sharing forum where school principals and support teachers would exchange notes with university lecturers on how best to carry out teaching practica. They would, in a unitary voice, address students to explain what they expect from the students. These fora could be used to unpack the contents of the SBS or teaching practice manual and other relevant documents and, where-ever necessary, re-draw the lines.

\subsection{Supervision and Assessment}

- The success of the teaching practicum is largely dependent on the quality of relationship among the triad consisting of the university supervisor, the cooperating teacher and the student teacher (Graham, 2006). The triad's level of communication, their understanding of objectives, and quality assessment of student achievements are major criteria for a successful practicum. Universities should seriously consider providing cooperating teachers with requisite training or adequate information to effectively perform their roles of ensuring a positive and progressive practicum experience for the student teacher

- Support teachers should be given more control in the partnership where they are allowed to assess the students. This is due to the fact that they are the ones who spend the larger part of time with the students during practica. This arrangement would boost the teachers' morale which would have a ripple effect on the way they would in turn treat the student teachers under them.

\subsection{Consultations}

- Support school authorities and university authorities should meet regularly to share experiences and update each other on the latest trends in teacher education and to as well get the opportunity to explain what each member of the partnership ought to do to render the practicum more effective. Lecturers should consult more with support teachers in order to discuss and find solutions to challenges faced by students in the schools. Pre- and post-lesson discussions should be done in the presence of support teachers.

- Support teachers should be inducted or work-shopped on the expectations of the university on issues of the 
practicum as outlined in policy documents.

\section{Conclusion}

The objectives of this inquiry were to examine the pre-teaching campus-based studies and preparations done before student teachers are deployed for school-based studies or teaching practice. An attempt was made to establish the perceptions of the school principals and mentor-teachers about the effectiveness of pre-deployment preparedness of student teachers before deployment to these schools as well as examine the varying roles of individual members of the practicum triad comprising the university, the student teacher and the school during the practicum component of primary teacher education at the University of Namibia.

After establishing the facets of the school participation in the triad which are most effective in supporting student teachers throughout their school based practicum, suggestions were collated from practicum schools, student teachers and the University of Namibia's Faculty of Education in order to model an effective partnership strategy for teaching practica for primary school teacher training in Namibia.

\section{References}

Cohen L., Manion, L., \& Morrison, K. 7th Ed., (2011), Research Methods in Education. Routledge, New York

Cruickshank, D. \& Aramalin, W. (1986). Field experiences in teacher education: Considerations and recommendations. Journal of Teacher Education, 37(3), 34-40.

Darden, G., Darden, A., Scott, K., \& Westfall, S. (2001). The student-teaching experience. Journal of Physical Education, Recreation and Dance, 72(4), 50-53.

Dobbins, R. (1996). Student teacher self-esteem in the practicum. Australian Journal of Teacher Education, 21(2). Retrieved from: http://ro.ecu.edu.au/cgi/viewcontent.cgi?article=1197\&context=ajte

Lincoln, Y.S., \& Guba, E.G. (1985). Naturalistic inquiry. Beverly Hills, CA: Sage Publications.

Masule, L. (2011) An Investigation into the merger between UNAM and Colleges of Education in Namibia, Leeds Metropolitan University/ Polytechnic of Namibia, Windhoek.

McIntyre, D.J., Byrd, D.M. \& Foxx, S.M. (1996). Field and laboratory experiences. In J. Sikula (Ed.), Handbook of research on teacher education (pp.171-193). New York: MacMillan.

Miles and Huberman, (1994).Qualitative Data Analysis: An Expanded Sourcebook, UK: Sage Publications

Murtaza A 2011, Comparative Study of Teaching Practice in Teacher Training National Institute of Education - Singapore Teaching Practice . retrieved from http://www.nie.edu.sg/practicum/policies-procedures

Punch, K. (2009) Introduction to research methods in education. London, UK: Sage.

Purdy, N. \& Gibson, K. (2008) Alternative Placements in Initial Teacher Education: An Evaluation, Teaching and Teacher Education, 24, 2076-2086.

Rodgers, A. \& Keil, V. (2007) Restructuring a traditional student teacher supervision model: fostering enhanced professional development and mentoring within a professional development school context. Teaching and Teacher Education, 23 (1) (2007), pp. $63-80$

Russell, T. (2005). Using the practicum in preservice teacher education programs: Strengths and weaknesses of alternative assumptions about the experiences of learning to teach. The missing links in teacher education design, 135-152. Retrieved from http://www.springerlink.com/index/t5944u7nm1277811.pdf

School Based Studies Manual for Primary phases of the Bachelor of Education [Honours] programme (2014), University of Namibia.

Springer, K. (2010) Educational research: A contextual approach. Chennai: John Wiley and Son, Inc.

Springer, K. (2010) Educational research: A contextual approach. Chennai: John Wiley and Son, Inc.

Strauss, A.L., \& Corbin, J. (1990). Basics of qualitative research: Grounded theory procedures and techniques. Thousand Oaks, CA: Sage Publications.

Taggart \& Wilkinson (1988). The Effects of Self-Instruction on the Feedback Statements of Cooperating Teachers During Post-Teaching Conferences. South Pacific Journal of Teacher Education, Volume 16, Issue 1, 1988

Tannehill, D. \& Zakrajsek, D. (1988). What's happening in supervision of student teachers. Journal of Teaching in Physical Education, 8 , 1-12.

Tuli, F. \& File, G. (2011) Practicum experience in teacher education. Ethiop. J. Educ. \& Sc. Vol. 5 No 1 September 2009

Villers, H. \& Mackisack, V. (2011) Optimizing opportunities to learn during practicum: Developing collaborative partnerships between the university and school. University of Auckland, Auckland, New Zealand. Asia-Pacific Journal of Cooperative Education, 2011, 12(3), 183-194

Zeichner, K. M., \& Gore, J. (1990). Teacher socialisation. In W. R. Houston (Ed.), Handbook of research on teacher education. New York: Macmillan Publishing Company. 